\title{
A Lyapunov Based Approach to Enchance Wind Turbine Stability
}

\author{
A. Bennouk*, A. Nejmi, M. Ramzi \\ Mathematics and physics laboratory \\ Faculty of Sciences and Technics, Beni Mellal \\ Sultan Moulay Slimane University, Beni Mellal, Morocco \\ e-mail: bennouk.anasse@gmail.com
}

\begin{abstract}
This paper introduces a nonlinear control of a wind turbine based on a Double Feed Induction Generator. The Rotor Side converter is controlled by using field oriented control and Backstepping strategy to enhance the dynamic stability response. The Grid Side converter is controlled by a sliding mode. These methods aim to increase dynamic system stability for variable wind speed. Hence, The Doubly Fed Induction Generator (DFIG) is studied in order to illustrate its behavior in case of severe disturbance, and its dynamic response in grid connected mode for variable speed wind operation. The model is presented and simulated under Matlab/ Simulink.
\end{abstract}

Keywords: Double Fed Induction Generator, wind turbine, Rotor Side Converter, Lyapunov, Grid Side Converter

\section{Introduction}

Today, the number of wind turbines connected to the grid is steadily increasing. Variable speed wind turbines outperform constant speed turbines in aerodynamic efficiency while also reducing stress on the mechanical apparatus so as to make it more productive and cost-effective [1].

Double Fed induction generator (DFIGs) is becoming more used in modern wind power generation systems due to their variable speed operation, four quadrant active and reactive power regulation, low converter cost, and reduced power losses compared with Permanent Magnet Synchronous generators (PMSG).

Classic control of grid connected to DFIG is usually based on VOC (Voltage Oriented Control) or FOC (Flux Oriented Control), it decouples the $\mathrm{d}$ and $\mathrm{q}$ rotor currents in the synchronous frame. Control of instantaneous active and reactive power is then achieved by regulating the decoupled rotor currents, using proportional-integral (PI) parameters and accurate machine parameters. The weakness is shown when the machine's converters operate beyond their linear limits [1].

Field Oriented Control (FOC) is improved in this paper by the use of Backstepping strategy to control the Rotor Side inverter; this method has scored positive performances. This kind of control is generally associated with Lyapunov functions in order to increase system stability against variable wind fluctuations.

Moreover, Variable structure control or Sliding Mode Control (SMC) strategy is an effective and a high-frequency switching control for nonlinear systems showing uncertainties. It features simple implementation disturbance rejection, strong robustness and fast responses. This method will be used in the Grid Side inverter control so as to enhance Udc stability and then reach the grid parameters in term of frequency, Total Harmonics Distortion (THD) and voltage unbalance [2].

This paper is organized as follows: the second section is due to deal with a wind energy modeling under Matlab/Simulink. The third section illustrates the Field Oriented Control and Backstepping linearization control for the rotor side converter. The fourth section introduces a SMC destined to control of the Grid Side Converter performances. Finally, a simulation with its inherent results will be presented. 


\section{Wind Turbine Modeling}

This section presents WECS based on a DFIG connected to the electric grid

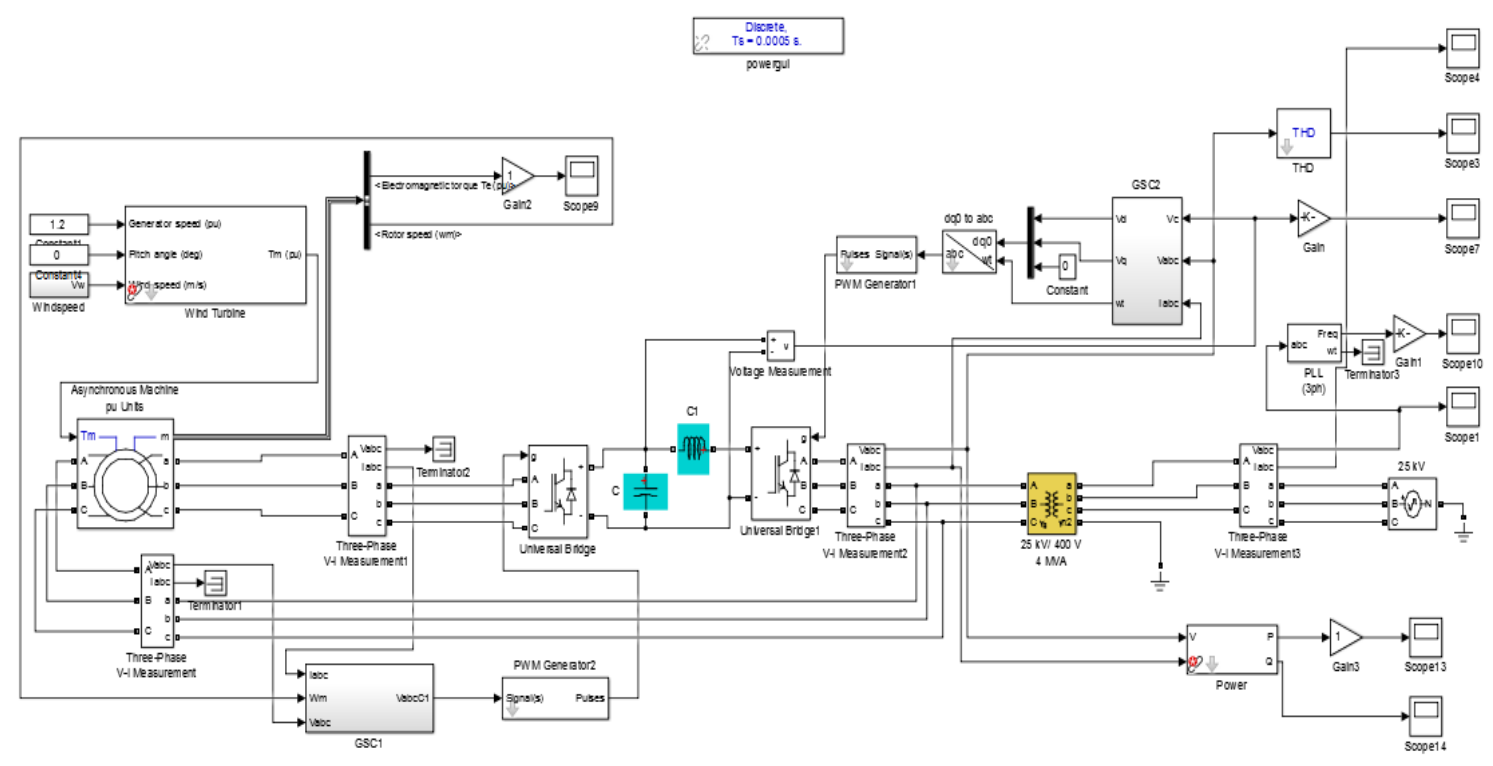

Figure 1. Wind turbine based on DFIG

Figure 1 shows the scheme of electrical energy's generation from the wind power on the basis of DFIG. As it is demonstrated, the stator is connected directly to the grid whereas the rotor is connected to the grid via a Back-to-back converter [2].

\subsection{Wind Speed Model}

Wind speed model contains four components [1]:

$$
V_{w}(t)=V_{b}(t)+V_{r}(t)+V_{n}(t)+V_{g}(t)
$$

where $V_{b}$ is the base wind component (constant), $V_{r}$ is the ramp wind component, $V_{n}$ is the base noise wind component and $V_{g}$ is the gust wind, $V_{g}$ is set to zero during simulation, all of them in $\mathrm{m} / \mathrm{s}$. The model implementation of the wind speed in Matlab/Simulink is presented in Figure 2:

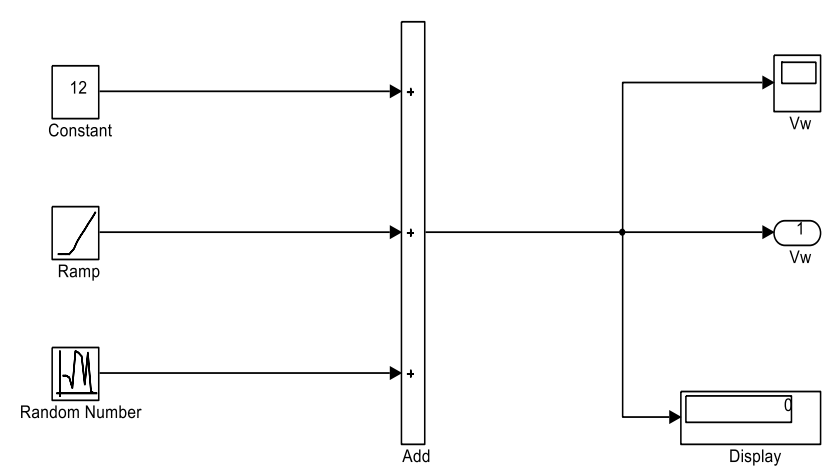

Figure 2. Wind speed model

IJEEI Vol. 5, No. 1, March 2017: $145-154$ 
The kinetic energy in this level is given by:

$$
P_{w}=\frac{1}{2} m v^{2}=\frac{1}{2} \rho S v^{3}
$$

where $\mathrm{m}$ is the air mass, $\rho$ is the air density, $v$ is the wind speed and $S$ is the covered surface of the turbine.

\subsection{Wind Turbine Modeling}

Wind turbine is applied to convert the wind energy into mechanical torque. The mechanical torque of the turbine can be calculated from mechanical power at the turbine extracted from wind power. Then, the power coefficient of the turbine (Cp) is used. The power coefficient is function of pitch angle $(\beta)$ and tip speed $(\lambda)$. The power coefficient maximum of $\left(\mathrm{C}_{\mathrm{p}}\right)$ is known as the limit of Betz [2].

The power coefficient is given by:

$$
C_{p}=C_{1}\left(\frac{C_{2}}{\lambda i}-C_{3} \beta-C_{4}\right) e^{-\frac{C 5}{\lambda i}}+C_{6} \lambda
$$

where

$$
\frac{1}{\lambda_{i}}=\frac{1}{\lambda+0.08 \beta}-\frac{0.035}{\beta_{3}+1} \text { and } \lambda=\frac{\omega_{m} \cdot R}{v}
$$

$\mathrm{C}_{1}, \mathrm{C}_{2}, \mathrm{C}_{3}, \mathrm{C}_{4}, \mathrm{C}_{5}$ and $\mathrm{C}_{6}$ are constants given by the turbine constructor $\left(\mathrm{C}_{1}=0.516, \mathrm{C}_{2}\right.$ $=116, C_{3}=0.4, C_{4}=5.1, C_{5}=21$ and $\left.C_{6}=0.0068\right), R$ is the rotor radius and $\omega_{m}$ is the rotor speed generator. The power coefficient is a nonlinear function of the tip speed ratio $\lambda$ and the blade pitch angle $\beta$ (in degrees).If the swept area of the blade and the air density are constant, the value of $C_{p}$ is a function of $\lambda$ and it is maximum at the particular $\lambda$ optimum. Hence, to fully utilize the wind energy, $\lambda$ should be maintained at $\lambda_{\text {opt }}$, which is determined from the blade design, $C_{p}$ is defined as [3]:

$$
C_{p}=\frac{P m}{P w} \leq 1
$$

and

$$
\mathrm{P}_{\mathrm{m}}=\frac{1}{2} \mathrm{C}_{\mathrm{p}} \rho S v^{3}
$$

where $P_{m}$ is the mechanical output power of the turbine.

The Rotor Side converter is used to extract the MPPT (Maximum Power Point Tracking), in this purpose the DFIG angular speed reference is calculated permanently with an approach to follow the wind speed fluctuation, the wind turbine control generates the DFIG speed reference signal, performed by the RSC controller in DFIG control level. This reference signal is determined from the predefined characteristic P- $\omega$, based on filtered measured generator speed. Whereas the Grid Side Converter is used to control the DC link voltage and guarantees unity power factor in the rotor branch. The transmission of the reactive power from DFIG to the grid is thus only through the stator, a conventional vector with Lyapunov approach will be used in this command algorithm to enhance system stability.

\section{Rotor Side Converter control}

The standard vector control is used to control the RSC. In order to ensure stability when applying this control strategy mechanism, the stator flux magnitude must remain constant. To this purpose, Lyapunov's approach is used in order to enhance the system's stability [2]. d-q frame :

The electrical energy conversion is described by the following equation according to a 


$$
\begin{aligned}
& V_{s d}=R_{s} i_{s d}+\frac{d \varphi s d}{d t}-\omega_{s} \varphi_{s q} \\
& V_{s q}=R_{s} i_{s q}+\frac{d \varphi s q}{d t}+\omega_{s} \varphi_{s d} \\
& V_{r d}=R_{r} i_{r d}+\frac{d \varphi r d}{d t}-\omega_{r} \varphi_{r q} \\
& V_{r q}=R_{r} i_{r q}+\frac{d \varphi s q}{d t}+\omega_{r} \varphi_{r d}
\end{aligned}
$$

and

$$
\begin{aligned}
& \varphi_{s d}=L_{s} i_{s d}+L_{m} i_{r d} \\
& \varphi_{s q}=L_{s} i_{s q}+L_{m} i_{r q} \\
& \varphi_{r d}=L_{r} i_{r d}+L_{m} i_{s d} \\
& \varphi_{r q}=L_{r} i_{r q}+L_{m} i_{s q}
\end{aligned}
$$

Electromagnetic torque is expressed by:

$$
\mathrm{Te}=\frac{P}{\Omega}=\frac{P \cdot p}{\omega}=p\left(\varphi_{s d} i_{r q}-\varphi_{s q} i_{r d}\right)
$$

$V$ is the voltage, $R_{s}$ and $R_{r}$ are respectively the stator and rotor resistance. $L_{s}, L_{r}$ and $L_{m}$ are stator, rotor and mutual inductance between stator and rotor $\theta_{\mathrm{s}}$, and $\theta_{\mathrm{r}}$ present angles of stator and rotor frames.

The aim of this approach is to catch the MPPT and to stabilize active power through regulating the electromagnetic torque depending basically on $\mathrm{i}_{\mathrm{rq}}$ and $\mathrm{i}_{\mathrm{rd}}$, the stator flux is, thus, oriented to $d$ axis in order to simplify the equations [5], [6]:

$$
\begin{aligned}
& V_{s d}=0 \text { and } V_{s q}=\omega_{s} \varphi_{s q} \\
& V_{r d}=R_{r} i_{r d}+\frac{d \varphi_{r d}}{d t}-\omega_{r} \varphi_{r q} \\
& V_{r q}=R_{r} i_{r q}+\frac{d \varphi s q}{d t}+\omega_{r} \varphi_{r d}
\end{aligned}
$$

The new system inputs are respectively $d$-q rotor current and angular speed expressed by the following equations:

$$
\begin{aligned}
& \frac{d i r d}{d t}-\frac{1}{L r} v r d-\frac{R r}{L r} \operatorname{ird}+\omega r i r q\left(\frac{L s \cdot L r-M^{2}}{L s \cdot L r}\right) \\
& \frac{\mathrm{d} \varphi \mathrm{rq}}{\mathrm{dt}}=V r q-\text { Rsird }-\omega r \varphi r d \\
& \frac{\text { dirq }}{\mathrm{dt}}=-\frac{1}{L r} v r q+\left(\frac{M^{2}}{L s L r}-\omega r\right) i r d-\frac{M \omega r}{L r L s \omega s} V s q-\frac{R r}{L r} i r q \\
& \frac{\mathrm{d} \omega}{\mathrm{dt}}=\frac{C r}{J}-\frac{B}{J} \omega-\frac{K \varphi \text { sdirq }}{J}
\end{aligned}
$$

IJEEI Vol. 5, No. 1, March 2017: $145-154$ 
It is clear from the dynamic model above, the nonlinearity, because of the coupling between the d-q rotor currents and the speed, a variable change is initiated so as to introduce the Lyapunov function:

$$
\begin{aligned}
& y_{1}=\omega_{c}-\omega \\
& y_{2}=i_{r d r e ́ f}-i_{r d} \\
& y_{3}=i_{\text {rqréf }}-i_{r q}
\end{aligned}
$$

$\omega$ is the angular speed, $\omega_{c}$ is the reference of $\omega, i_{r d}$ and $i_{r q}$ are respectively the $\mathrm{d}$ and $\mathrm{q}$ axis rotor current, , $i_{\text {rdréf }}$ and $i_{\text {rqréf }}$ are their references.

Lyupunov function is chosen as :

$$
\begin{gathered}
\mathrm{V} 1=\frac{1}{2}{y_{1}}^{2} \\
\dot{V}_{1}=y_{1} \dot{y}_{1}=y_{1}\left(\dot{\omega}_{c}-K p \varphi_{s d} i_{r q}+\frac{B}{J} \omega+\frac{C r}{J}\right)
\end{gathered}
$$

The derivative of the complete Lyupunov function is negative defined, if the quantities between parentheses in equation (12) are equal to zero. $\mathrm{i}_{\text {qref }}$ is given by:

$$
\begin{aligned}
& i_{\text {rqref }}=\frac{1}{K p \varphi s d}\left(C r+B . \omega+2 . J \cdot K \cdot y_{1}\right) \\
& \dot{\mathrm{y}} 2=\imath d r \dot{e} f-\imath_{r d}-K y_{2}+K y_{2}
\end{aligned}
$$

and

$$
\dot{y} 3=1 \dot{r e f}-\dot{r_{q}}-\mathrm{K} y_{3}+\mathrm{K} 3
$$

$\mathrm{V} 2$ and $\mathrm{V} 3$ are defined respectively as :

$$
\mathrm{V} 2=\frac{1}{2}{y_{1}}^{2} \text { and } V 3=\frac{1}{2} y_{3}{ }^{2}
$$

Lyapunov function is defined as:

$$
\begin{gathered}
\mathrm{V} 4=\frac{1}{2}\left({y_{1}}^{2}+{y_{2}}^{2}+{y_{3}}^{2}\right) \\
\dot{V 4}=-K{y_{1}}^{2}-K{y_{2}}^{2}-K{y_{3}}^{2}+y_{2}\left(\text { ldire } f-i_{r d}+K y 2\right)+y_{3}\left(\text { lq } \dot{r} e f-i_{r q}+K y 3\right)
\end{gathered}
$$

In order to fulfill Lyapunov's conditions, we integrate the following equations [2]:

$$
A 1=y_{2}\left(\text { ldiref }-i_{r d}+K y_{2}\right)=0
$$

and

$$
A 2=y_{3}\left(\text { lqref }-\imath_{\dot{r q}}+K y_{3}\right)=0
$$

We conclude after calculating direct and quadrature voltage that :

$$
\mathrm{V}_{r d}=-K L_{r} y_{2}-R_{r} i_{r d}+\omega_{r}\left(L_{s} L_{r}-\frac{M^{2}}{L s L r}\right) i_{r q}
$$




$$
\mathrm{V}_{r q}=-K L r y_{3}+\left(\frac{M^{2}}{L_{s} L_{r}}-L_{r} \omega_{r}\right) i_{r d}+\frac{M \omega r}{L_{s} \omega s} \mathrm{~V}_{s q}+R_{r} i_{r q}
$$

\section{Grid Side Converter control}

When the grid voltage changes suddenly, a control approach is adopted in the GSC to keep the DC voltage constant and to assure a zero rotor reactive power [7], [8], [9].

First, the system equations are defined as follows:

$$
\begin{gathered}
U d=-L \frac{d i d}{d t}-R i_{d}+\omega L i_{q}+v d \\
U q=-L \frac{d i q}{d t}-R i_{q}-\omega L i_{d}+v q \\
\mathrm{C} \frac{\mathrm{d}}{\mathrm{dt}} v d c=i_{d c}=i_{L}-i_{d}
\end{gathered}
$$

$\mathrm{U}_{\mathrm{d}}, \mathrm{U}_{\mathrm{q}}: \mathrm{d}-\mathrm{q}$ components of converter voltage

$v_{d}, v_{q}: d-q$ grid voltage components

$\mathrm{i}_{\mathrm{d}}, \mathrm{i}_{\mathrm{q}}: \mathrm{d}$-q current components

We suppose that the grid voltage is aligned to the d-axis. We may define the state system as [10]:

$$
\begin{aligned}
{\left[\begin{array}{c}
i d \\
l q \\
v d c
\end{array}\right] } & =\left[\begin{array}{cc}
-R / L & w \\
w & -\frac{R}{L} \\
-1 / C & 0
\end{array}\right]\left[\begin{array}{l}
i d \\
i q
\end{array}\right]+\left[\begin{array}{c}
-\frac{U d}{L}+\frac{v d}{L} \\
-1 / L U q \\
i L
\end{array}\right] \\
\mathrm{y} 1 & =i d \\
\mathrm{y} 2 & =v d c+i q-i L \\
\mathrm{~S} 1 & =y 1 \text { ref }-y 1 \\
S_{2} & =y 2 \text { ref }-y 2
\end{aligned}
$$

In order to keep the system stability, the sliding system should be:

$$
S_{2} \cdot \dot{S}_{1} \leq 0 \text { and } S_{2} \cdot \dot{S}_{2} \leq 0
$$

Then we deduce the Ud and Uq :

$$
\begin{aligned}
\mathrm{U}_{d} & =K \operatorname{sign}\left(S_{1}\right)-R i_{q}+L \omega i_{d}+v_{d} \\
\mathrm{U}_{q} & =K \operatorname{sign}\left(S_{2}\right)+i_{d} L\left(\omega-\frac{1}{C}\right)-R i_{q}+\left(i_{L}-\dot{i}_{L}\right)
\end{aligned}
$$

\section{Simulation and results}

The test wind profile with full field turbulence is generated through the use of Wind turbine block as presented in Figure 1. This block shows the hub height wind speed profile. In general, wind speed consists of two components, mean wind speed and turbulence component. The simulation is realized in order to illustrate Grid parameters stability, Grid voltage unbalance, THD and Frequency.

The wind turbine and DFIG parameters are illustrated in Table 1 [11]:

IJEEI Vol. 5, No. 1, March 2017: $145-154$ 
Table 1. DFIG parameters

\begin{tabular}{ccc}
\hline Parameter & Symbol & Value \\
\hline Active Power & $\mathrm{P}$ & $2 \mathrm{MW}$ \\
Stator resistance & $\mathrm{Rs}$ & $0.001518 \Omega$ \\
Stator inductance & $\mathrm{Ls}$ & $0.059906 \mathrm{H}$ \\
Rotor inductance & $\mathrm{Lr}$ & $0.082060 \mathrm{H}$ \\
Rotor resistance & $\mathrm{Rr}$ & $0.002087 \Omega$ \\
Mutual inductance & $\mathrm{Lm}$ & $2.4 \mathrm{H}$ \\
Pole pairs & $\mathrm{N}$ & 2 \\
Inertia & $\mathrm{J}$ & $17.23 \mathrm{Kg} \cdot \mathrm{m}^{2}$ \\
Gear box & $\mathrm{n}_{\mathrm{g}}$ & 5.065 \\
\hline
\end{tabular}

Simulation and results are presented first with a constant wind profile, then during a variable wind speed to illustrate the used approach robustness based on Lyapunov theory:

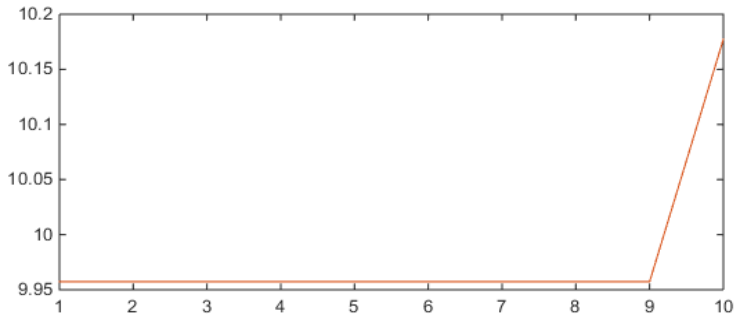

Figure 3. Wind speed

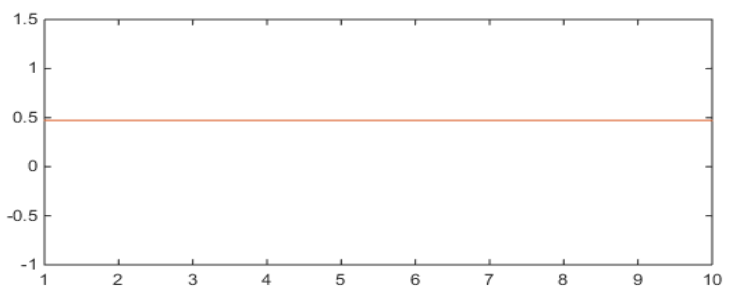

Figure 5. Power Coefficient (Cp)

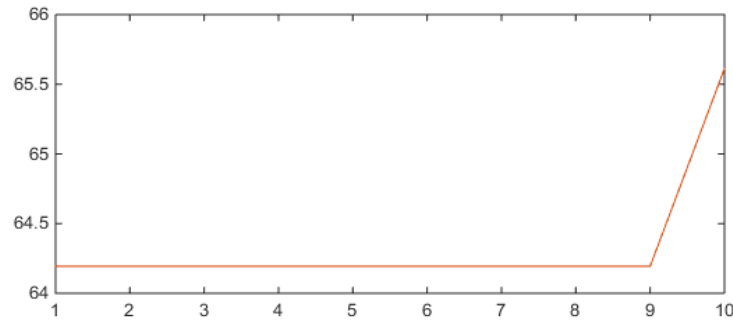

Figure 4. Rotor angular speed

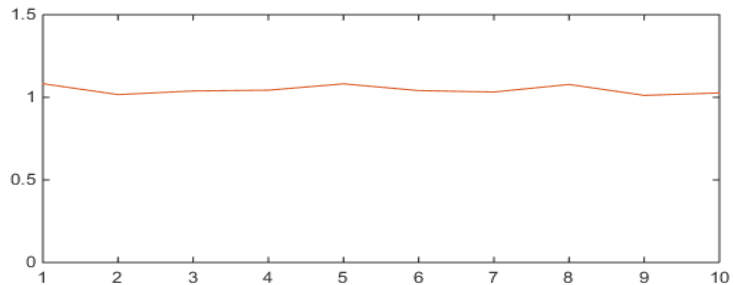

Figure 6. Vdc

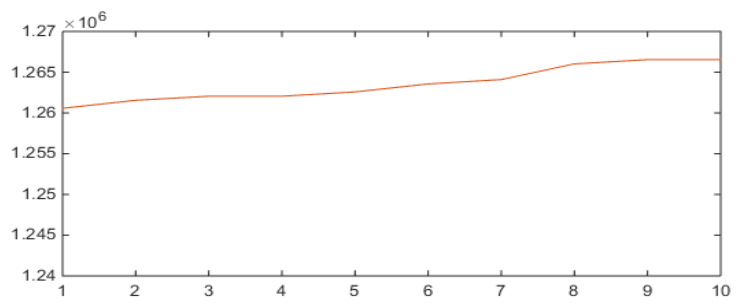

Figure 7. Active Power 
It's obvious that for a constant wind speed,the wind power captured and deliverd to the grid had the same shape as the wind, active power is kept constant and equal to $1.26 \mathrm{MW}$ for a wind speed of $9.9 \mathrm{~m} / \mathrm{s}$, the MPPT approach is well achieved and the power coeffiscient is maintained at 0.47 . The DFIG speed is the image of the wind speed, it is following properly its reference. Lyapunov apporach used to control GSC shows also good performances and the Udc voltage was equal to its reference.

We present here simulations result following variable wind speed :

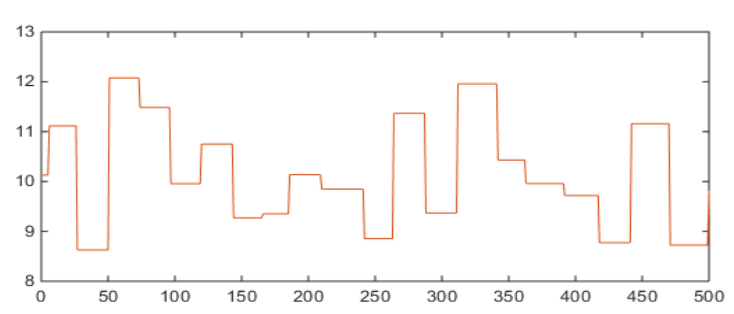

Figure 8. Variable wind speed

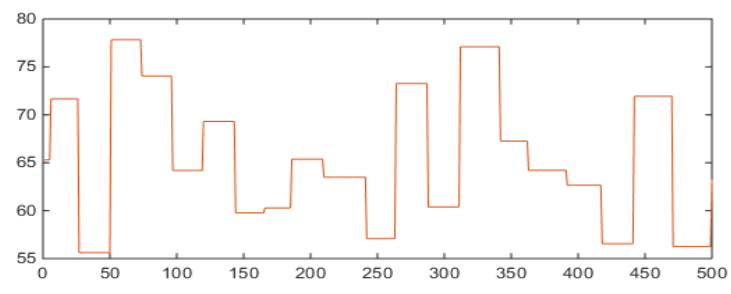

Figure 10. Rotor angular speed

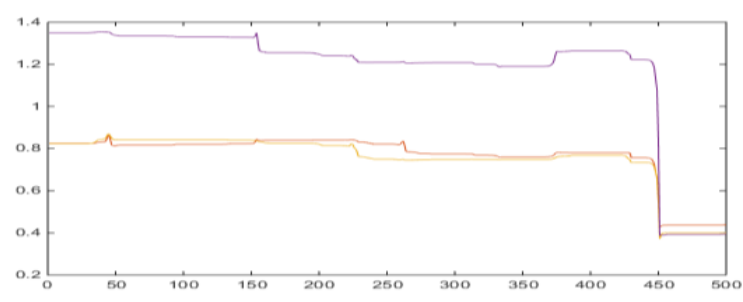

Figure 12. Total Harmonics Distorsion (THD)

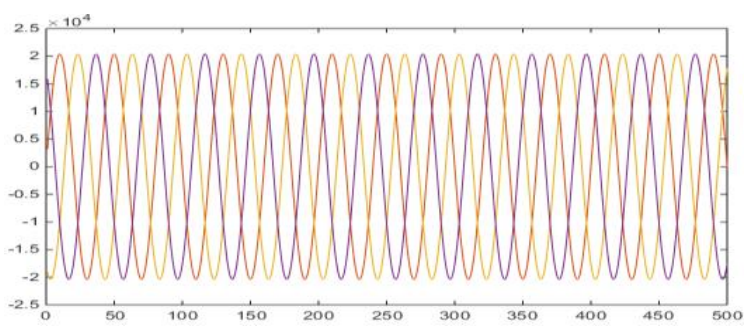

Figure 14. Grid voltage

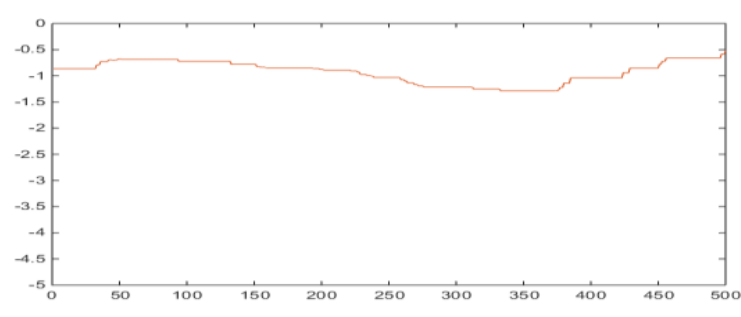

Figure 9. Electromagnetic torque

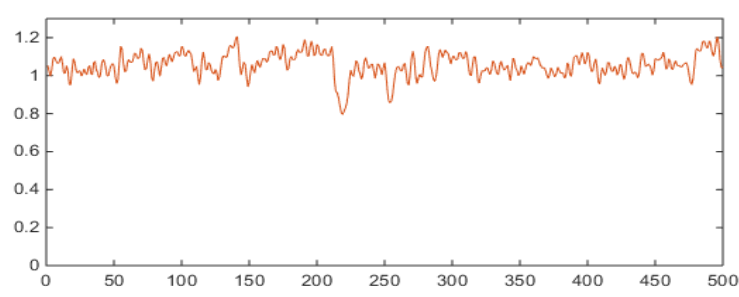

Figure 11. Vdc voltage

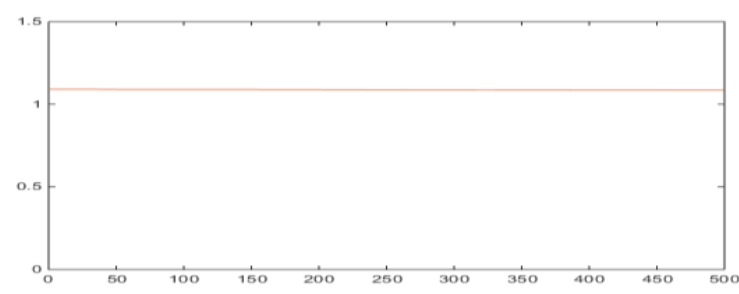

Figure 13. Frequency

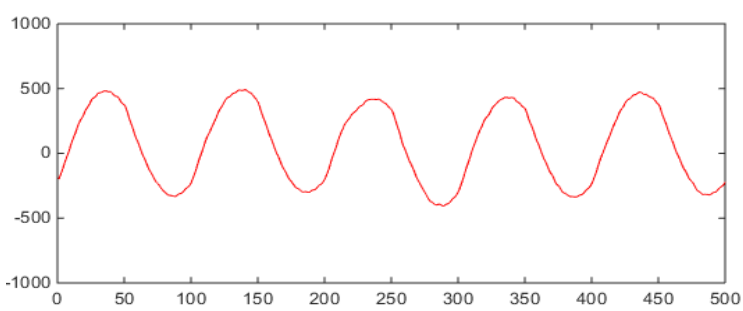

Figure 15. Grid Current

IJEEI Vol. 5, No. 1, March 2017: $145-154$ 


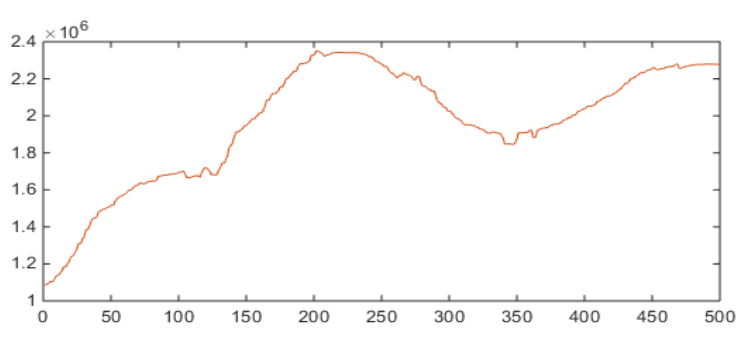

Figure 16. Active power

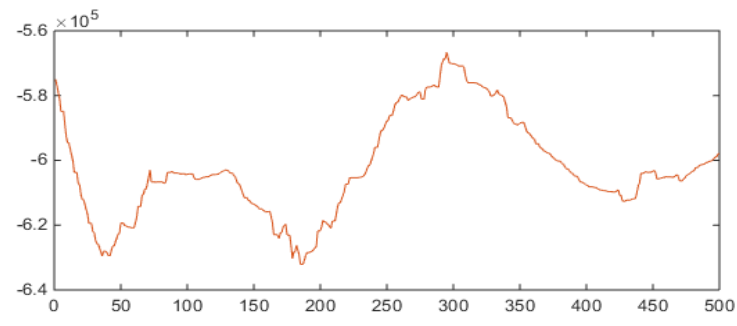

Figure 17. Reactive power

The dynamic responses of the DFIG generation system under an intermittent wind action are shown in Figure 8. It is clear that when a mean wind speed changes, the electromagnetic torque varies. We may deduce then that when the wind speed increases $11 \mathrm{~m} / \mathrm{s}$, the electromagnetic field is set at $1 \mathrm{pu}$. Consequently, the delivered power is more or equal to $2 \mathrm{MW}$. Conversely, when the wind speed is inferior, the electromagnetic and active power generated decreases proportionally. The DFIG speed is the image of the wind speed, it is following properly its reference

The DC link voltage also varies according to the wind speed fluctuations, but the variation is not obvious as shown in Figure 11 . The DC voltage is generally kept at its reference.

The Total Harmonic Distortion presented in Figure 12 had demonstrated good performances and did not exceed 5\%, the assigned threshold of national grid code. The frequency, as shown in Figure 13, did not also exceed the threshold of $1.2 \mathrm{pu}$. The grid side voltage had shown also good performances apart from some a slight distortion caused by dynamic response and wind speed fluctuations. The balance voltage remained inferior to $1 \%$, which is the fixed threshold of National Grid Code [2].

The active power variations illustrated in Figure.16 depend and follow the wind speed variation which has demonstrated also good performances. The active power reaches its highest values when the wind speed exceeds $11 \mathrm{~m} / \mathrm{s}$.

The reactive power had shown a good performance as presented in Figure.17 except in 200 s, when we observe that the reactive power exceeds 600 Kvar following a quick fluctuation of Udc link voltage.

\section{Conclusion}

With the growing level of penetration scored by wind-origin power production into the general power system, many national codes have been applied so as to ensure stability to the electric grid. Many simulations and complete models are needed to be established prior to any connection between wind farm and electric grid [2].

A nonlinear control of variable speed WT is, thus, proposed. The main aim here is to maximize the energy capture from the wind while reducing Grid parameters deviations.

Also, and with the aim of illustrating from one side the system stability and to what extend it matches the national grid code, we have identified and presented the THD, frequency and voltage unbalance in the Point of Common Coupling (PCC), as these parameters had shown when they were under their limit during the simulation time.

Stability had been improved by using FOC and Lyupunov conditions in the Generator Side Converter. In the Grid Side Converter, SMC control was applied. The different PID controllers had been turned so as to obtain good performances. The use of SMC associated to Lyapunov had also demonstrated good performances in terms of Grid parameters stability. 


\section{References}

[1] Hu J, Nian H, Hu B, He Y, Zhu ZQ. Direct Active and Reactive Power Regulation of DFIG Using Sliding -Mode Control. IEEE. 2010; 25(4): 1028-1039.

[2] Bennouk A, Nejmi A, Benamou A, Ramzi M. Backstepping and MIMO approachs to control a wind turbine based on DFIG. International Journal of Emerging Technology and Advanced Engineering. 2016; 6(3): 12-17.

[3] Mullane A, Lightbody G, Yacamini R. Adaptive Control of Variable Speed Wind Turbines. Rev. Energ.: Ren. Power Engineering. 2001; 101-110.

[4] Bossouf B, Karim M, Lagrioui A and Taoussi M. Backstepping Control of DFIG Generators for WideRange Variable-speed Wind Turbines. Int. J. Automation and Control. 2014; 8(2): 122-140.

[5] Song Y.D, Dhinakaran B, Bao X.Y. Variable speed control of wind turbines using nonlinear and adaptive algorithms. Journal of Wind Engineering and Industrial Aerodynamics. 2000; 293-308.

[6] Beltran B, Ahmed-Ali T, Benbouzid M. Sliding Mode Power Control of Variable-Speed Wind Energy Conversion Systems. IEEE Transaction Energy Conversion. 2008; 23 (8): 551-558.

[7] Khemiri N, Kheder A, Faouzi M. An Adaptive Nonlinear Backstepping Control of DFIG Driven by Wind Turbine. WSEAS Transactions on Environment and Development. 2012; 8(2): 60-71.

[8] Beltran B, Ali T, Benbouzid M. Sliding Mode Power Control of Variable-Speed Wind Energy Conversion Systems. IEEE. 23(2): 551-558.

[9] Rajendran S, Jena D. Backstepping Sliding Mode Control of a Variable Speed Wind Turbine For Power Optimization. Journal of Modern Power Systems and Clean Energy. 2015; 3(3):402-410

[10] Sung-Hun L, jun Joo Y, Juhoon Back, Jin-Heon S, Ick C. Sliding Mode Controller for Torque and Pitch Control of PMSG Wind Power Systems. Journal of Power Electronics. 2011; 11(3): 342-349.

[11] Li S, Haskew T.A, Williams K.A, Swatloski R.P. Control of DFIG Wind Turbine With Direct-Current Vector Control Configuration. IEEE. 2012; 3(1): 1-11. 